\title{
Diagnosis of Renal Stones with Underlying Metabolic Abnormalities Using FTIR Spectroscopy
}

Sir,

There are few reports on renal stone diseases in children in the Indian literature. The diagnosis of underlying metabolic disorders causing renal stones in children seems almost nil ${ }^{1-5}$. The importance of Fourier Transform Infra Red (FTIR) spectroscopic stone analysis of the kidney stone in guiding the work up of children with underlying metabolic disorders is emphasized in this brief communication.

Between $2005-2007$, there were eleven patients who presented with renal and upper urinary tract stone disease (kidney, ureters) with the principal author. The stag horn stones and the multiple stones in kidneys were subject to open surgery after a biochemical metabolic work up. The stones that were removed after surgery were sent for analysis by FTIR spectroscopy. Other biochemical tests were done after FTIR spectroscopy gave a clue to the nature of the stones. Three children with metabolic stones were diagnosed. One child had multiple pure uric acid stones producing acute renal shut down and another had multiple pure cystine stones with associated Pelvi-ureteric junction obstruction which presented severe hypertension. The third child had xanthine stones. The FTIR spectroscopy picture of the cystine stones is shown in Fig. 1. Four patients who were having small stones in the kidney are asymtomatic and they are under careful follow up Their calcium and creatinine spot tests were normal. The diagnosis of metabolic stones was facilitated in the three children by FTIR spectroscopic analysis of the

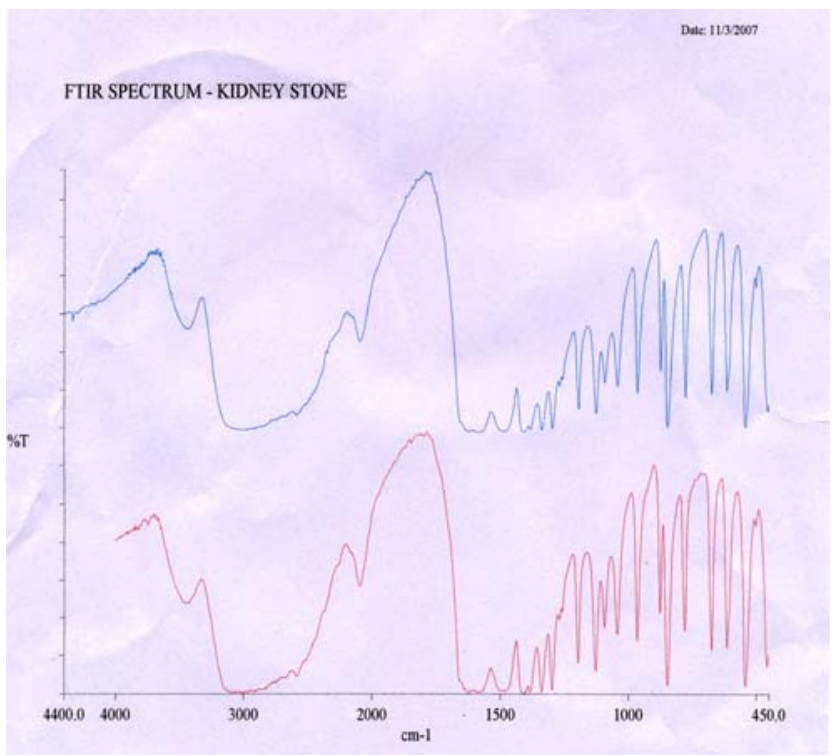

Fig. 1. FTIR spectroscopy of a child with pure cysteine stone. stone. The child with cystine stones presented with recurrent stones on the left kidney due to non compliance to treatment after starting therapy. The child with uric acid stones is currently on urinary alkalinisation and allopurinol therapy and has normal biochemical renal functions. The child with xanthine stones is on high oral fluid regime.

The reports of diagnosis of metabolic renal stones in childhood in India have been scanty. A large study by Ahlawat $e t$ al which used X-ray diffraction studies has failed to pick up a single cystine stone in 434 renal stones ${ }^{1}$. Use of FTIR spectroscopy in stone analysis has been done in children earlier ${ }^{2}$. It is important that renal stones recovered from patients are subject to correct technique of stone analysis. This analysis will guide the further metabolic tests to be performed. The FTIR spectroscopic analysis is fast, and can pick up the correct molecules The resultant spectrum represents the molecular absorption and transmission, creating a molecular fingerprint of the sample. Infrared spectroscopy can result in a positive identification of every different kind of material.In conclusion, three children with metabolic abnormalities and renal stone disease were picked up by preliminary stone analysis using FTIR spectroscopy. This is a technique physicians must be aware in order to benefit patients with renal stones.

\section{K.L. Narasimhan, Balpinder Kaur, Deepti Suri ${ }^{1}$ and J.K. Mahajan Department of Pediatric Surgery ${ }^{1}$ and ${ }^{1}$ Pediatrics, Postgraduate Institute of Medical Education \& Research, Chandigarh,India.E-mail: narasimhankl@gmail.com} [DOI-10.1007/s12098-009-0100-7]

\section{REFERENCES}

1. Ahlawat R, Goel MC, Elhence A. Upper urinary tract stone analysis using X-ray diffraction: Results from a tertiary referral centre in northern India. The Natl Med J India 1996; 9: 10-12.

2. Ansari MS, Gupta NP, Hemal AK, Dogra PN, Seth A, Aron $\mathrm{M}$ et al. Spectrum of stone composition:structural analysis of 1050 upper urinary tract calculi from northern India. Int J Urol 2005; 12: 12-16.

3. Harrache D, Mesri A, Addou A, Semmound A, Lacour B, Daudon M. Urolithiasis in children in West Algeria. Annals Urology 1997; 31: 84-88.

4. Pak CY, Poindex JR, Adams-Huet B, Pearle MS. Predictive value of kidney stone composition in the detection of metabolic abnormalities. Am J Med 2003; 115: 26-32.

5. Chaim JB, Gearhart JP, Peters CA. Collecting system. In Oldham KT, Colombani PM, Foglia RP, eds. Surgery of infants \& children: scientific principles $\mathcal{E}$ practice. Philadelphia, PA; Lippincot-Raven publishers, 1997; 1481-1542. 